\title{
SUPERVISION FOR OUR TIMES: COUNTERTRANSFERENCE AND THE RICH LEGACY OF THE BUDAPEST SCHOOL
}

\section{Raluca Soreanu ${ }^{1}$}

\begin{abstract}
In this paper I ask what an investigation of the Budapest model of supervision adds to our psychoanalytic imaginary. The Budapest model confronts us with a number of crucial questions for contemporary psychoanalysis, including the question of envisaging ways of working on the countertransference of the analyst to their patient. I discuss the forgetfulness that surrounds the Budapest model, and I read it in relation to the unsettling issues it stirs up, including those of authority, horizontality, and the ethics of psychoanalysis. In this model, supervision can be seen as a form of "double dreaming" or of "dreaming up of a dream". In particular, in drawing on the writings of Sándor Ferenczi and Michael Balint, I point to some principles behind the Budapest model and to the epistemic, technical, and ethical implications of their ideas. I also work toward a Ferenczian "translation" of the idea of "parallel process".
\end{abstract}

Keywords: The Budapest School of Psychoanalysis, Sándor Ferenczi, Vilma Kovács, Michael Balint, supervision, countertransference, Budapest model of supervision.

How we remember and evoke, in our times, the practices and habits that belonged to other psychoanalytic times and places, is no small matter. This remembrance of other practices is hardly just a matter of keeping an "accurate" historical record, where past psychoanalytic modes of doing and thinking are stored. It is of direct consequence to our contemporary psychoanalytic imaginary and to what we come to conceive as possible in our field. The question I engage in this paper is what we might gain in terms of the psychoanalytic imaginary of supervision by a close investigation of the problem of the Budapest model of supervision. The Budapest model is not a "fossil" in a "museum" of long-disappeared psychoanalytic practices. Instead, it confronts us with a number of questions of crucial relevance for contemporary psychoanalysis, including the question of envisaging ways of working on the countertransference of the analyst to their patient. I also discuss the forgetfulness, and even secrecy, that often surrounds the Budapest model of supervision, and I read it as a form of defense in relation to the unsettling issues that this supervision model stirs up, including issues of authority, horizontality, and the ethics of psychoanalysis. 
In what follows, I reconstruct the conditions of forgetting the creativities of the Budapest School of psychoanalysis and its tradition on supervision. In the Budapest model, the first training case was supervised by one's own analyst. As I show, far from marking a lack of reflexivity on the dangers that this practice bears in relation to transforming the candidate's analyst into a figure of hyper-authority, this model was developed as a good-enough solution to the problem of placing countertransference at the center of the psychoanalytic dispositif and at the center of the transmission of psychoanalytic knowledge. In so doing, my aim is not to "revive" the practice, as such, that the Budapest School model of supervision brings into focus. Instead, I outline the structure of questions that grow out of investigating the practice, and that have a transversal echo, cutting across different psychoanalytic schools, orientations, and geographic locations. One such question is: what is an adequate "place" for working systematically on the analyst's countertransference to their patient? I argue that remembering the Budapest School confronts us with the extreme difficulty of this question and with the fact that no other model of supervision to date has found an entirely satisfactory answer to it.

In the 1920s, something at the heart of psychoanalytic reflection on supervision was lost, never to be found again. The entire dispositif of supervision was formed around this fundamental loss. With the exclusion of the practices of the Budapest model, the challenging questions it asked were excluded as well. What we are left with is an impoverished story that marks the confrontation between two traditions, the Berlin model and the Budapest model, where the Berlin model prevailed, while the Budapest model was cast out. In the 1940s and 1950s, Michael Balint (1948, 1954) made an important incision into this simplifying story and evoked the controversies and unresolved issues that characterized the 1920s. While this was a resonant intervention, it arguably 
did not manage to alter the main narrative, which treats the Budapest model of supervision as an exotic and even dangerous collection of practices that we have now successfully overcome.

In the past decade, some voices have revived the memory of the Budapest model of supervision (Szőnyi, 2014; Bacal, 2016) and have pointed to the internal diversity of the practices that are subsumed under this tradition, and to the importance of adding some more colors to the image we hold of those early supervision times. One of our main sources of insight into the Budapest model is Vilma Kovács's ground-breaking article on "Training- and Control-Analysis," written in 1936. In the past two decades, the reflection on countertransference in the frame of supervision has itself known a revival, especially in the writing of authors of the intersubjective tradition, but not restricted to them (Berman, 2000, 2014; Leader, 2010; Yerushalmi, 2012, 2018). What I propose in these pages is to draw these two threads together, and to give an account of the spirit and principles behind the Budapest School peculiarity of having one's own analyst also serving the function of one of the supervisors of a training case.

In so doing, I draw on the writings of Sándor Ferenczi and Michael Balint and point to the epistemic (what is psychoanalytic knowledge?), technical (through which dispositifs is psychoanalytic knowledge transmitted?), and ethical (what is the position of the psychoanalyst in relation to knowledge and authority?) implications of their ideas, in relation to supervision. The guiding image, which I place at the heart of the present investigation (and at the heart of the Budapest School of psychoanalysis) is that of transference and countertransference as a single system (Haynal, 1999). ${ }^{2}$ Ultimately, I discern some Ferenczian principles for supervision, and I tie them into the contemporary debates, especially by working towards a Ferenczian "translation" of the idea of "parallel process" (Arlow, 1963; Searles, 1955; Doehrman, 1976) in supervision. 
Let us return for now to our difficult question: why remember Budapest? And also: of what nature is the forgetfulness that began in the 1920s, and continues to our days? The first reason for this forgetting has to do with the difficulties of psychoanalysis in telling its own history in terms of traumas and splits, both internal and external, to the field of psychoanalysis. In their essay "Why Psychoanalysis Has No History", Elisabeth Young-Bruehl and Murray Schwartz (2012) comment on a regression of psychoanalytic history-writing into biographic writing, memorializing, or criticizing Freud. What is creating this proliferation of fragmented stories is the fact of not acknowledging the trauma history of psychoanalysis (Soreanu, 2019). The trauma relates in important ways to the different waves of migration of psychoanalysts before and during the First and Second World Wars, mostly to England and to the Americas, and to its deep consequences in terms of dislocation and communal fragmentation (Young-Bruehl and Schwartz, 2012, p. 140). What is missing, for Young-Bruehl and Schwartz, is a collective historical consciousness that can organize a set of disparate observations precisely as a trauma history, a reflection on "a repetitive pattern of splits and consequent distortions" (Young-Bruehl and Schwartz, 2012, p. 142). In other words, it is deeply political to insist on tackling the traumatic residues resulting from both historical events and from intellectual splits, quarrels, and fragmentations internal to the field of psychoanalysis. We can say that there is a flaw in telling psychoanalytic histories, which externalizes traumas, rather than treating them as internal and constitutive of our current state of practice and debate.

The second reason is closely related to the first one and refers to the kind of "object of memory" Sándor Ferenczi himself is in psychoanalysis. As we know, Ferenczi and Freud exchanged more than a thousand letters (see Freud \& Ferenczi, 1908-1914; 1914-1919; and 19201933). The theoretical labor that took place in the pages of this correspondence marks 
psychoanalysis to this day. In 1933, there was an important split between the two. As many writers have shown (Bergmann, 1996; Haynal, 1997; Schneider, 1988), this split had traumatic consequences in psychoanalysis and led to a forgetfulness around Ferenczi's contributions to psychoanalytic theory and technique that lasted for decades. In The Basic Fault, Michael Balint himself spoke of the magnitude of the consequences of the split between Freud and Ferenczi: "The historic event of the disagreement between Freud and Ferenczi [...] acted as a trauma on the psychoanalytic world" (Balint, 1968, p. 152). In the past two decades, we have seen a "Ferenczi revival" (Harris \& Kuchuck, 2015) with a growing interest in his work and complex legacies. The way the Budapest model of supervision is remembered (or forgotten) is tied in a significant manner to Ferenczi's figure and this traumatic forgetting.

The third reason is equally complicated, and it has to do with the mode of institutionalization of psychoanalysis, and with some of its defenses against accepting plural psychoanalytic modes of knowledge transmission and training. As Szőnyi (2014, p. 608) writes, linking the atmosphere of silence and even secrecy around the Budapest model with the early processes of institutionalization of psychoanalysis,

the fate of the Budapest model was total silence, internationally and in Hungary as well. I think that the international silence, which covered the whole training, especially the controversies on supervision [...] originated in the weakness of the organization of the time, which could not bear open debates on decisions achieved with difficulties.

This resonates with Michael Balint's (1948) argument in his important contribution "On the Psycho-Analytic Training System", where he reads the Berlin model as a defense against the particular modes of suffering caused to the first generations of analysts by the lack of structure of the years preceding 1920. In other words, the Berlin system was a move from almost no formal organization to a hyper-organization of the training. 
What we refer to as "the tri-partite model", "the Berlin model" or "the Eitingon model" of psychoanalytic training, consisting of theoretical courses, personal analysis, and clinical supervision, was introduced at the Berlin Psychoanalytic Institute in the early 1920s and was later accepted by most other training centers. Ferenczi expressed his objections in relation to the strict separation of the candidate's analysis from the work of supervision, as he thought that it would limit the student's "opportunity for continuous development through various methods of teaching" (Fleming \& Benedek, 1966, p. 12).

Where did Ferenczi's idea of a more plural method of training come from? It is possible to infer that it was anchored in the practices that were already established in the Budapest milieu. As early as 1915 , Ferenczi was already hoping for the opening of a psychoanalytic social clinic, that could give access to treatment to those who could not afford it. After a sustained struggle in the dire political times of Horthy's regime, the Budapest Polyclinic opened its doors in December 1931. With the clinic, Friday meetings became regular, and they brought together Sándor Ferenczi, Alice and Michael Balint, Vilma Kovács, and also Endre Almássy, Robert Bak, Lilly Hajdu, Imre Hermann, István Hollós, Kata Lévy, Edit Ludowyk-Gyömröi, Sigmund Pfeiffer, Géza Róheim, and Lilian Rotter. Senior analysts gave lectures, and they were followed by a seminar in psychoanalytic technique, led by Vilma Kovács (Soreanu, 2019).

Here, cases were presented and discussions on countertransference were given a key place. It is also here that the particularities of the Hungarian training system stabilized, making the analysis of the countertransference of the analyst to their patient an essential part of psychoanalytic training. This is discussed in 1936 by Vilma Kovács (1936) in her paper on training and control analysis. In the Hungarian training system, the first case was supervised by the training analyst themselves, which allowed the emergence of a designated analytic place-indeed, not an 
uncomplicated one-for working primarily on the countertransference of the trainee to their patient, and only secondarily on their technical skill. Although transference and countertransference were conceived of as a system, where one element could never be fully extricated from the other, it was important to find the most suitable arenas and arrangements for the labor with countertransference. Hungarian analysts believed that only one's analyst is in the position to develop the sensitive knowledge needed for judging the candidate's character, their conflicts, and their modes of reaction, so as to allow sufficient work on the countertransference to take place.

Let us imagine what this model entailed. Although it was not always the case (Szönyi, 2014, pp. 606-607), it was possible for supervision to take place while the analyst was lying down on the psychoanalytic couch. The analyst, therefore, was in the dreamer's position. While lying on the couch, they were "dreaming up" the patient, in the presence of their supervisor/analyst. Freeassociation was thus "structurally" written into the situation. By "not moving place" from the couch, or, rather, by finding themselves on the same couch at a different time, the analyst's unconscious was "spoken to" via the arrangements of the dispositif of supervision, and their hopedfor "response" was one where they could mobilize to an equal extent conscious and unconscious processes in the work of supervision.

It is important to disentangle a particular "knot" here, by evoking the discussions on the institutionalization of training, which took place in the international meetings of the $20 \mathrm{~s}, 30 \mathrm{~s}$ and 40s. It is a misconception that the discussions were a kind of competition between two "models" — the Budapest and the Berlin—where the Budapest model was discarded for its inappropriate condensations of the analyst-supervisor roles. Balint makes an important correction to such an image: 
It was agreed that to the analysis of the student's reactions to his patient's transference more importance should be given [...], but at the same time it was stressed that teaching of analytical technique exemplified on the material of the candidate's supervised cases was equally important. To emphasize the difference between the two tasks, the one (analysis of the candidate's counter-transference to his patient) was called "Kontrollanalyse" the other (teaching the student how to analyse a patient presenting different problems from his, the student's, own) was called "Analysenkontrolle". It soon became clear that for conducting "Kontrollanalyse" the training analyst was the most suitable person and conversely for the "Analysenkontrolle" he was not. (Balint, 1948, p. 166).

In other words, while there was widespread agreement with the principle of the Budapest training system, there was no practical follow-up in terms of the formalization of training. This "place" for work on countertransference remained an ideal. My point here is not so much to champion the Hungarian system, but to point to the fact that in the past nearly eighty years there has been an arrest in the psychoanalytic imagination on training, and an inhibition to organize any sort of revision to it. Balint opened his 1954 paper on training with the following sentence: "The greatest mistake we could make would be to consider our present training system as a final, or even settled, solution of our many problems" (Balint, 1954, p. 157). And he added: "semper reformari debet $-[\ldots]$ 'reform, unremittingly'.” (Balint, 1954, p. 162).

What is of interest here is Balint's insistence on dreaming up more spaces where countertransference can be addressed. This is his Budapest legacy. Alice and Michael Balint (1939) argue that in teaching candidates how to conduct an analysis, we cannot ignore an omnipresent "variable': who the analyst is. The second "variable" of equal importance is the psychoanalytic dyad and its singular functioning, including the vicissitudes of this functioning: "the analytical situation is the result of an interplay between the patient's transference and the analyst's counter-transference, complicated by the reactions released in each by the other's transference on to him" (Balint \& Balint, 1939, p. 227). 
We are already in the position to orchestrate a few de-exoticizing interventions in relation to the Budapest model of supervision. The first one relates to seeing it in its internal heterogeneity (Szőnyi, 2014), but also as a composite model, where not all supervision experiences are to be had with one's own analyst. The dreaming-up of the patient taking place on the couch is only one of the varieties of supervision found in this model. Only one of the training cases is supervised by one's training analyst, while others can be the object of "regular" face-to-face supervision with other analysts, or of group supervision/discussions.

The second intervention happens around the boundaries between "analyst" and "supervisor". These boundaries can never be strictly concrete, but they are always unconsciously invested, in a way that includes multiple transferences and countertransferences. As Berman (2000, p. 276) argues: "We might think of supervision as the crossroads of a matrix of object relations of at least three persons each bringing her or his psychic reality into the bargain, creating a joint intersubjective milieu". But this "at least three persons" often includes a fourth position, that of the analyst of the analyst. Even if we are situated within or without the Budapest model of supervision, we are just the same within this complex matrix of object relations: the matters of the "analyst in the supervisor" and of the "supervisor in the analyst" are bound to be of great importance. ${ }^{3}$ It is relevant to ask ourselves how these positions play out in the unconscious of the analyst in training. Furthermore, it is an illusion that countertransference work can be consigned to the candidate's analysis (Berman 2000, p. 274). Assuming that it is possible to relegate countertransference work to the analysis and technical work on the case to the supervision is not an instance of good boundaries, but an instance of a defense by splitting which is written into the very dispositif of supervision. 
The third intervention is one of situating the Budapest model of supervision in the context of the Budapest School's wider explorations with countertransference. Notably, the practice of having one of the training cases supervised by one's own analyst does not present itself to us as some abstract principle to be followed and not questioned, but it emerges as bound to experience, including the experience of the supervisor. In Vilma Kovács's (1936) exposition, we learn about her difficulties in "orienting" herself in the material presented by the supervisees, in the situations when the presenter is not her analysand as well. As she writes: "I did not know the candidate's character and his modes of reaction, and so I could not say from what point of view he was judging the various situations he encountered" (Kovács, 1936, p. 352). In Kovacs's experience, "Analysenkontrolle" without "Kontrollanalyse" was superficial and unsatisfactory, because countertransference could not adequately be worked on by the supervision pair.

It seems that the most important question of Budapest analysts was "what to do about countertransference?". This question is equally present in Michael Balint's explorations, in particular in his experiment with "Balint groups," which has its roots in Budapest in the 1930s, but which he later developed in England in the 1950s (Mészáros, 2009, p. 217; Kutter, 2002). In the groups, medical doctors present cases that come with particular difficulties to them, while the leaders make interventions that are meant to create a psychoanalytic mindset, a psychoanalytic way of working on the cases, and stable modifications in the personality of the doctors and in the manner they approach the doctor-patient relationship.

In Balint groups, the case is spoken, and the presentation is free-associative. In the groups, Balint insisted on doctors not using notes when making their interventions. When the case is spoken, and presented to the group, the basic assumption is that there is something yet to be uncovered. Neither the presenter, nor his peers, nor the group leader know exactly what is being 
sought. Most importantly, comparisons between cases are comparisons between cases of countertransference. I believe that Balint, through his work with groups, was aiming to refine his understanding of and his vocabulary on countertransference. The intention was not so much to "apply" psychoanalysis outside its usual frame, but to design yet another "place" where countertransference could be observed. Balint (1970) made a direct connection between case presentation in the Balint groups and the Hungarian system of supervision: in both, the cases presented are treated as a "dream text".

The powerful question "what to do about countertransference?" partly explains our resistance in engaging the Budapest model of supervision, in its richness and its creativities. A complex context of forgetfulness, which I evoked above, is making the Budapest model ever more distant. In a recent paper Szőnyi (2014, p. 606) writes: “In 1987, Klára Ajkay conducted interviews among Hungarian training analysts about how they see the Budapest model. Unfortunately, this lecture, given in New York, remained unpublished". We might wonder about the nature of this failure to inscribe in the public domain an archive of practices and experiences of a model that poses such difficult questions to us today. It has perhaps more to do with the psychoanalytic field's reluctance to engage the specters of Budapest, rather than with the destiny of an individual unpublished paper.

\section{FERENCZIAN PRINCIPLES FOR SUPERVISION IN OUR TIMES}

Sándor Ferenczi did not leave us writings about supervision, but several of his papers (Ferenczi, 1929, 1932a, 1933) contain ideas on the epistemic status of psychoanalysis (what is psychoanalytic knowledge?); technical elucidations on transmission (through which dispositifs is psychoanalytic knowledge transmitted?); and ideas on the ethical position of the analyst (what is the position of the psychoanalyst in relation to knowledge and authority?). By examining some 
Ferenczian insights that have direct relevance to supervision, we also place supervision firmly within metapsychology: our psychoanalytic knowledge about unconscious transmission and the functioning of dyads surely cannot be suspended when we approach the topic of supervision. (For a Ferenczian discussion of supervision see also Kupermann, 2018).

In what follows, I show in which way a turn to Ferenczi's metapsychology and ideas on technique helps us to develop new insights about the situation of supervision and to arrive at a paradigm of supervision for our times. I define "in our times" by a kind of binding commitment to examine the countertransference: whatever psychoanalytic "times" are yet to come, we must insist that they don't turn away from more and more work dedicated to the understanding of countertransference.

Ferenczi brings a useful complication to Thomas Ogden's statement that "the supervisor helps the analyst to dream" and "It is the task of the supervisory pair to "dream up' the patient, that is, to create a 'fiction' that is true to the supervisee's emotional experience with the analysand" (Ogden, 2005, p. 1265). In other words, the supervisor's role is to help the supervisee dream the elements of his experience with the patient that the analyst has previously been only partially able to dream (their "interrupted dreams", Ogden, 2004, p. 857), or has been almost entirely unable to dream (their “undreamt dreams", Ogden, 2004, p. 857).

A Ferenczian supervision, I argue, is one where a "double dreaming" or a "concentric dreaming" is taking place: a dream within another dream, or a dream dreaming a dream. ${ }^{4}$ The accent is thus on there being two dreams; and on the relationship between the dreams. This "double dreaming" means that the supervisor's technique allows them to always hold in mind both the first dream (even if this is a "small" dream, or an "interrupted" dream, to keep to Ogden's terms) and the second dream, emerging in the here-and-now between the supervisor and the supervisee. The 
supervisor does not reduce the first dream to the second dream or vice versa; nor blend the dreams into a single master-dream where the original dreams become fused; but remains aware that the two dreams can interact in an intricate manner; and, it is also a part of the supervisory pair's work to register these transmissions that take place between one dream and another. In contrast to Ogden's image, we would not say that in supervision "an interrupted dream begins again" or "an undreamt dream is dreamt", but that "a dream (or its absence) is being told within a dream". As such, the supervision situation is always triadic and contains references to three presences (the patient, the analyst, and the supervisor) and to two acts of dreaming (the analyst is dreaming the patient; the supervisor is dreaming the dreaming of the patient).

As soon as we settle this image of "double dreaming" in place, we can hold on to Ferenczi's insights on power and authority in the analytic situation, so as to realize that this image is to a large extent an ideal. For Ferenczi, the horizontality of the analytic space, which he often mentions, especially in The Clinical Diary (Ferenczi, 1932a), is a constant aspiration and struggle, not a given. Horizontality is a verb for Ferenczi, and the analyst (supervisor) must constantly strive for it, despite hierarchizing impulses that come from their own unconscious, from the unconscious of the patient (supervisee), and from the very structure of the analytic (supervisory) encounter. In other words, just like the analytic situation, the supervision situation reconstitutes the originary situation of infantile obedience. Here, Ferenczi's (1933) conception of the "identification with the aggressor" is crucial and his paper on the "Confusion of Tongues..." maintains its relevance.

I would like to evoke here a lesser-known and earlier writing, titled "Taming of a Wild Horse", where Ferenczi (1913) discusses the nature of authority and submission. In this short text, he offers a minute description of the actions of a "horse whisperer", who manages a successful domestication of a wild horse. The key of this domestication is neither force and imposition nor 
mild and gentle seduction, but a fast alternation between the two, capable of "breaking" the animal, by causing it an unbearable intensity and the confusion of unmet expectations, in terms of the registers of address (from love to dread, in a tight sequence) (Soreanu, 2018a, p. 64). The tamer seems to make precise tactical use of his knowledge about the effect of the juxtaposition of love and dread, and he first uses affectionate stroking and monotonous lulling talk, followed by authoritative and compelling loud-voice commands. Ferenczi (1913) calls the first tactic "maternal hypnosis", and the second "paternal hypnosis". With this complicated event of submission, the capacity for independent action is lost, and so is the capacity for doubt. The subject comes to ignore the validity of their own psychical and physical experience, and delegates judgements to an external force (Soreanu, 2018a, p. 64).

Returning to the situation of supervision, my reading of Ferenczi's insights on power and authority is that they point us to a key principle of supervision: above and beyond the mere transmission of technical psychoanalytic knowledge, the role of the supervisor is to watch over the re-emergence of scenes of infantile obedience and to watch over their own tactics of maternal hypnosis and paternal hypnosis in relation to the supervisee. The very fact that the supervisor is a different person from one's own analyst is no guarantee that the inescapable issue of submission to authority will be handled in an adequate or creative manner. Furthermore, the idea that the problems of infantile obedience are in some way "reserved" to one's own personal analysis, and therefore the supervision situation can be "free" from them, is just as anti-psychoanalytic as it is illusionary. It appeals to a way of transmission of knowledge that stands outside transference and countertransference, which is a psychoanalytic impossibility. Irrespective of the "model" of supervision that we are discussing, the question of the "supervisor in the analyst" and the "analyst in the supervisor" remains consequential. The struggles around maternal hypnosis and paternal 
hypnosis (for both supervisor and supervisee) thus meet us as already "democratized" across the different models of supervision.

In his 1948 paper on training systems, Michael Balint compared the atmosphere in psychoanalytic training with "primitive initiation ceremonies" (Balint, 1948, p. 167) having as their goal "to force the candidate to identify himself with his initiator, to introject the initiator and his ideals, and to build up from these identifications a strong super-ego which will influence him all his life" (1948, p. 167). To further explain his critique, Balint reminded us of one of Ferenczi's innovative contributions to the understanding of a "mad" part of the superego, that is formed through processes of identification with the aggressor and through the incorporation of the guilt of the aggressor: "superego intropression" (Ferenczi, 1930, p. 227). I argued that this superego is the result of the introjection not of an object or of an aspect of an object, but of a scene. It is a superegoas-a-scene (Soreanu, 2018a, p. 218; Soreanu, 2018b). This scene circulates in the psyche, incessantly replaying the violent encounter between an "over-great (fat) aggressor" and "a much smaller, weaker person, oppressed and dominated by the aggressor" (Ferenczi, 1930, p. 228). The context of supervision can be particularly vulnerable to scenes of "superego intropression", where a "mad" and unexamined aspect of the functioning of authority (in the institution or in the supervisor) is pushed onto the supervisee, with greatly damaging consequences for the strength of their ego, for the severity of their superego, and for institutional processes and psychoanalytic transmission on the whole. ${ }^{5}$

Given these challenges, what could constitute a horizontalizing intervention in the context of supervision? Ferenczi talks about "conviction", which, as opposed to mere "belief", cannot be derived solely through logical insight; instead, it needs to be lived as an affective experience, and even felt in one's body (Ferenczi, 1912, pp. 193-194). Supervision is a space for the developing 
of convictions, and not of beliefs. The supervisor's intervention can be qualified as psychoanalytic knowledge if it can be lived equally as an intellectual, affective, and corporeal experience, in relation to the "dreaming-up" of the patient that the supervisee brings in the room.

This takes us to another very important topic: that of regression in the frame of supervision. Several contemporary voices have discussed the way in which psychic phenomena pertaining to primary process manifest themselves in the supervision situation or can even be seen as inherent to the structure of the supervision situation (Cassorla, 2001; Doehrman, 1976; Frijling-Schreuder, 1970; Yerushalmi, 2012; see also Bollas, 1987; and Spurling, 2008). While it would be impossible to review here all the contributions that Ferenczi brings to the topic of regression, I ponder on one of his lesser-known concepts, that of "gnosis", which is connected to a time of "reliving" the trauma and to a return to a pre-traumatic time. In his writing The Two Extremes: Credulity and Skepticism, Ferenczi speaks of "psychognosis" or "gnosis", which he sees as "the hope that it is possible, through an adequate profound relaxation, to gain access to a direct path to a past experience, which can be accepted without any other interpretation as being true" (Ferenczi, 1932b, p. 263). Here, the pre-traumatic time and the post-traumatic time touch. "Psychognosis" does not mean direct access to the experience "of how things truly were", but an effect of authenticity and an effect of veridicity (Soreanu, 2018a, p. 71). The post-traumatic state is, paradoxically, fuller in possibilities for enrichment and more radically relational than the pretraumatic state. In a similar way, the supervisor's interventions can be neither "true", nor "veridic", nor "authentic". To the extent that these interventions are managing to create an effect in handling difficult case material, they can also be judged to have created an effect of veridicity in the work of "dreaming up a dream" or of "double dreaming" that the supervision entails. In his short piece on "gnosis", Ferenczi adds: "In fact there is in the end something that cannot, need not, and must 
not, be interpreted —or else analysis becomes an endless substitution of emotions and ideas mostly by their opposites" (Ferenczi, 1932b, p. 263). The work of supervision is similarly exposed to the risks of overinterpretation and of the endless turning of ideas into their opposites.

A final creative disturbance in the house of ideas on supervision, via the work of Ferenczi, relates to the notion of "parallel process". In the past few decades, instead of gaining more shape, this term has become somewhat flat, by being coded mostly via a system of projective identifications (Issacharoff, 1982), where, in short, the psychic experiences that the analyst has with the patient in the analytic frame are re-enacted between the analyst and the supervisor in the supervision frame. (For some key contributions on "parallel process" see Arlow, 1963; Searles, 1955; Doehrman, 1976; and Ogden, 2005). Ogden (2005) argues that a return to Searles' groundbreaking paper (1955) on the reflection process-which led to the formulation of the parallel process-might be a more fruitful starting point. As Searles describes it:

The emotions experienced by a supervisor-including even his private, "subjective" fantasy experiences and his personal feelings about the superviseeoften provide valuable clarification of [unconscious interpersonal] processes currently characterizing the relationship between the supervisee and the patient. In addition, these processes are often the very ones which have been causing difficulty in the therapeutic relationship. [...] The [conscious and unconscious] processes at work currently in the relationship between patient and therapist are often reflected in the [conscious and unconscious] relationship between therapist and supervisor [...] I shall refer to this phenomenon as the reflection process. (Searles, 1955, pp. 157-59).

If we remain faithful to the idea of the supervision space as "double dreaming" or the "dreaming up of a dream", then it becomes clear that a focus on the re-enactment of the first dream in the second dream is one-sided. An insistence on the aspects of the analysis that are "paralleled" in the supervision might point to a resistance to elaborating the singular transference phenomena that take place in the relationship between the supervisor and the supervisee (Stimmel, 1995, p. 609). This might mean that the tendency of the supervisor is to attribute the difficulties or conflicts 
of the supervisory relationship to the patient, while treating the supervisory dyad as a reflection surface for the analytic dyad. As Berman (2000, p. 280) rightly points out, some aspects of the supervisory relationship are, simply put, "unparalleled", while the deadlocks of supervision at times develop above and beyond any psychic phenomenon we might think of as "parallel" process. The Budapest School's attention to countertransference (including the countertransference of the supervisor) leads to a special place given to these "unparalleled processes", and, ultimately, to the radical singularity of each supervisory dyad.

In a Ferenczian paradigm, the "double dreaming" of supervisory situation has radical potential, because it is at the same time a case of "double witnessing". The supervisor is the witness of the analyst's witnessing. The scene of trauma is thus addressed in a "double frame", where the suffering that was denied recognition has the best chances of being acknowledged.

\section{VIGNETTE: WITH COUNTERTRANSFERENCE AT HEART}

In this vignette, we meet a supervisor and a supervisee who have worked together for six years, on four different clinical cases, out of which one was a training case. The supervisor also experienced the work of the supervisee in the frame of group supervision, for two years; and had good familiarity with the supervisee's functioning in the institution. In one session, the supervisee arrives distressed by the intention of one of her patients to terminate the analysis. This was a severely traumatized patient whom the supervisee had been seeing for over two years, twiceweekly. The analysis had advanced at a fast pace, it was very rich, and significant progress was made. The risk of a negative therapeutic reaction was present and acknowledged, as the patient had made a previous attempt to terminate the analysis. The supervisee was able to make suitable interventions in this first instance, and the patient continued the analysis. 
In the supervision session, going over the details of the last session with the patient, the supervisee shared her great sense of loss and sadness over this potential termination. In a moment of heightened emotion, the supervisee says to the supervisor: "This was one of my most important patients, if not the most important, I've learnt so much with him." The supervisor listens, pauses and asks the supervisee: "Do you read Thomas Mann?". The supervisee responds that yes, she knows the work of Thomas Mann. The supervisor continues: "In Thomas Mann, in The Magic Mountain, those whose tuberculosis is gravest are also the most important. They are the most valued." The supervisee pauses as well. It is an intervention that is felt very strongly at the time, but that will also have significant and enduring effects in the supervisee's clinical work.

After the session, the supervisor's condensed image becomes very generative, it is the source of various chains of association. But let us stay with the image of the hierarchy of illness in Thomas Mann. Thomas Mann's The Magic Mountain [Der Zauberberg] (1924) is set in the years preceding WWI, from 1907 to 1914, in a tuberculosis clinic in the Swiss Alps. It spans seven years in the life of the protagonist, Hans Castorp, who ends up residing at the clinic. It also portrays seven years of melancholia, lived under the sign of death and disease. The melancholic temporality is exacerbated by the stultifying routines of institutional life at the sanatorium. A generalized malaise flows through and between patients, visitors and staff.

At the sanatorium, people are no longer defined by their roles in the collective (as members of a family, or a professional organization, or a town, or a country), but they are classified in relation to their disease. This leads to a true hierarchy of illness, where the more severely ill command more respect and are more valued, which means that some patients exaggerate their symptoms. It is an entire social and psychic organization centered on illness. The sanatorium thus becomes a place for preserving illness rather than curing it. Hans Castorp arrives there as a visitor, 
but he is readily seduced by the routine of life at the clinic and by the melancholic social organization it brings.

Returning to the supervision frame, we can see that through a single intervention, the supervisor is able to point to an important impasse or blind spot in the countertransference of the supervisee, but also a potential impasse that affects the analyst's clinical practice more broadly. Because of the scope and depth of their work together, the supervisor is able to point the intervention to the invisible space between the analyst's cases. The supervisee's comment, "This was one of my most important patients...", triggers, by way of free-association, the supervisor's evocation of the social organization in The Magic Mountain. The supervisor knows that the supervisee is justified in her clinical ambition to be a psychoanalyst of difficult cases. But the supervisor also knows that this comes with particular risks. The role the supervisor takes on in this instance is to challenge ossified positions in the countertransference, which are rooted in the analyst's own complexes. This intervention would thus not be possible without having overseen the supervisee's work over a good number of years and having seen the supervisee act in different clinical and institutional contexts. This type of knowledge approximates the type of intimate knowledge that Vilma Kovács was invoking in 1936 as crucial for maintaining a good direction for the supervisor's interventions, in the context of her discussion on the Budapest model of supervision. While in our case the supervisor is not the analyst of the supervisee, as in the Budapest model, she intervenes on the basis of insights into the countertransference of the supervisee to her patient, which have been gathered over the years in different settings.

The reaction on the part of the supervisee is powerful, and it leads not only to a better understanding of the countertransference of the case under supervision, but also to an insight into the supervisee's clinical exercise on the whole. The supervisor did not wish to suggest that the 
supervisee is melancholic, but, by using a hyperbolic image (which is part of her supervisory style), the supervisor drew attention to a moment of unconscious "inequalitarian" treatment of the supervisee's patients and even to a silent "hierarchizing" of patients in accordance to how "difficult" they are or how much clinical challenge they bring. While it is crucial to work-through this danger constantly, it becomes stronger when we are the analysts of severely traumatized patients, who might call forth the omnipotent tendencies of the analyst, or the risk of a kind of furor sanandi.

The supervisor's intervention creates an intense reaction in the supervisee, precisely because it acts mainly by touching a blind spot in the countertransference of the supervisee, and not by instilling intellectual or technical knowledge. The supervisor's intervention thus acts akin to an analytic interpretation. Its force lies in unconscious communication. This is also what constitutes its effectiveness. The supervisee later reveals that she often goes in her mind to the image evoked by the supervisor. The clinical work it enables surpasses the individual case presented on the occasion. After the supervision session, the supervisee feels that the relationship between her clinical cases has changed, and the vertical axis of illness which was threatening to act unconsciously so as to order her cases is now experienced more like a horizontalized plane, where every case occupies a singular space, and no patient is felt as "more important". If we think about the countertransference to the difficult cases, the analyst had been too vulnerable to the demands coming from patients who manifest an unconscious wish to be treated like "the chosen" or "the favorite".

It is important to note that the supervisor's intervention was drawing on a literary image, and not on a reference to a paper on technique. The supervisor free-associated with the material presented, and the couple of analysts at work found themselves for a moment in the Magic 
Mountain by Thomas Mann. The supervisor found a way to point to a risk that affects all of us, with various intensities, in different moments: that of accepting the transference demand to melancholize the analytic space by adopting a too rigid position of "healer" in the countertransference.

\section{CODA: SUPERVISION FOR OUR TIMES}

What are we left with, after this incursion into the ideas of the Budapest School of Psychoanalysis? The first and most important principle (we may call it the "zero principle") is that of proceeding with countertransference at heart: the countertransference of the analyst to their patient, but also that of the supervisor to the analyst; and particular ways in which they influence one another. This is the content of the more enigmatic formulation that supervision is a form of "double dreaming". The first principle invoked above is that of avoiding the "superego intropression" (Ferenczi, 1930, p. 227), by arriving at a systematic way of addressing the problem of authority, which often takes the form of a sequence of acts of maternal hypnosis and paternal hypnosis on the part of the supervisor. The second principle is that of striving for walking the distance from belief to conviction, which includes a reception of the supervisor's intervention that is in equal measure intellectual, affective or corporeal. The third principle is that of not shying away from the manifestations of primary process in supervision, and in particular from the specific forms of regression that the supervision context might entail. Here, Ferenczi's (1932b) idea of "gnosis" is particularly relevant. The fourth principle firmly re-inscribes the idea of parallel process as a kind of "kaleidoscope" of the transference-countertransference system. Depending on which aspect of the process of the "dreaming of a dream" in supervision we might chose to focus on, the insights we arrive at are different. One of the most important things is to never reduce the supervision situation to a reflection screen of the analytic situation. Whatever mirroring system 
might be in operation, it is bound to be a mirroring that has its own distortions, specific to the singular supervisory dyad we are considering. At the intersection of these principles of supervision what emerges is not the transmission of technical knowledge, but of the ethical posture of the psychoanalyst at work, always ready to consider the polyphony ${ }^{6}$ of transferential phenomena and the grounds of their own certainties. ${ }^{7}$

From this perspective, it is an ethical imperative of every psychoanalyst, and of the psychoanalytic field on the whole, to keep investigating the specific content of any given law or rule, including the rules that organize the mainstream practices of supervision. As mentioned above, Michael Balint (1948) gives a very lucid account of the way in which a field of contestation on this topic was abruptly turned into a foreclosed topic. From the agreement, in principle, that work on the countertransference of the analyst must be inscribed in the system of training/supervision, the new London Standing Rules of 1947 practically banned the Budapest model, without finding other institutional solutions for the difficult puzzle of addressing the countertransference. $^{8}$

The direct consequence of this ethical imperative means a particular investment in "collecting" the most diverse accounts of how supervision is carried out, across psychoanalytic societies, orientations, and geographic locations. This is to say that our getting close to the Budapest model of supervision paradoxically leads us also away from it and invites us to take into consideration with equal interest other psychoanalytic houses and habits. What is called for is a nearly ethnographic sensitivity in collecting these polyphonic experiences of supervision across psychoanalytic cultures.

While it is beyond the scope of this paper to engage in such ethnographic exercise, there are two directions which seem distinctly important in enriching our imaginary on supervision. The 
first direction is understanding the place of group supervision in psychoanalytic training. Because of the multiple transferences at play, the group might provide meaningful answers when it comes to the question of de-hierarchizing interventions. Let us remember the "invention" of Helene Deutsch who introduced in the Vienna training a supervision seminar where two cases would be followed by the group over time: one case was presented by a trainee, while the other by and experienced analyst (Leader, 2010). As Darian Leader (2010, p. 230) stresses, this setting was very likely to challenge the ossified separations between analytic generations in a very creative way. It would have shown the trainees that the experienced analyst is also capable of committing errors, just as the trainee is capable of finding strikingly ingenious solutions to difficult clinical situations.

The second direction is understanding the "life" of supervision in the life of the analyst. In other words, what are the ways in which analysts across psychoanalytic cultures transform the supervision of training cases in life-long supervision? De-coupling the way we regard the experience of supervision on the whole from the necessary connection with receiving an institutional confirmation would be a crucial step in giving the supervision context all the creative weight it deserves. While we might still hold different views on the issue of "analysis, terminable or interminable" (Freud, 1937) I argue that in the sphere of supervision we would be much profited by a statement akin to "supervision, interminable!". It is a measure of the creativity of the analyst to organize a plurality of contexts in which they both give and receive supervision, as supervision is a privileged form of knowledge production in psychoanalysis, the only context known to us where we might be able to "double dream". To not contribute in significant ways to contexts of supervision, as either giving or receiving supervision, is indeed a morbid act, or a de-libidinization of psychoanalytic transmission. 
Thomas Ogden (2005) invites us to think of supervision as the space where the dyad at work has, at least occasionally, time to waste. Resonating with Ogden, I would say that complicated task of dreaming up of a dream, or "double dreaming" cannot possibly be met with time constraints or urgency. The dreamers do not know where the dreaming is heading, and therefore they do not know how long it will take (see Soreanu, 2016). Lisa Baraitser shows that in capitalistic times, the entire psychoanalytic exercise can be seen as anachronistic: a "waste of time", a time that cannot be accelerated, cannot be justified, and "constitutes a dwelling in an indeterminate persistent situation that can be experienced as interminable" (Baraitser, 2017, p. 17). As Ogden (2005, p. 1272) writes: "This sense of having all the time in the world, of having time to waste, to my mind, is a necessary element of the emotional background for an important kind of associative thinking in the analytic supervisory setting."

Staying with the habits and thoughts of the Budapest School of Psychoanalysis performs an intervention in the complicated forms of forgetfulness that affect psychoanalytic history. I argued here that in the 1920s, something at the heart of psychoanalytic reflection on supervision was lost, never to be found again. Thus, the entire dispositif of supervision was formed around this fundamental loss. With the exclusion of the practices of the Budapest model, the challenging questions around countertransference, horizontality, authority, and ethics that it asked were excluded as well. In 1983, Paul Roazen paints a striking picture of the culture of secrecy that surrounds issues of training and supervision in psychoanalysis. At the International Congress in Innsbruck in 1927, Helene Deutsch had presented a paper on training and supervision, Sandor Rado had discussed the curriculum, while Hanns Sachs had spoken about training analysis. The discussion of these three papers, however, remained behind the closed doors of the International Training Committee (Fleming \& Benedek, 1966; Roazen, 1983, p. 55), not available to the 
psychoanalytic community, and none of them was published. With this failure to inscribe the trace of the content of our rules on what constitutes a good dispositif of supervision, the danger is that of a melancholic psychoanalytic culture, which does not know what it has lost.

\section{ACKNOWLEDGEMENTS}

This article is dedicated to Fátima Lobo Amin. The author would like to thank Tereza Mendonça Estarque, Mônica Aguiar, Carlos Lannes, Judit Szekacs, Irina Culic, Stephen Frosh, Laurence Spurling and Hanoch Yerushalmi. The writing of this article was supported through a Wellcome Trust Fellowship in the Medical Humanities [Grant 200347/Z/15/Z].

\section{REFERENCES}

Arlow, J. A. (1963). The supervisory situation. Journal of the American Psychoanalytic Association, 11, 576-594.

Bacal, H. (2016). The Budapest School's concept of supervision: Michael Balint's legacy to the development of psychoanalytic specificity theory. In A. W. Rachman (Ed.), The Budapest School of Psychoanalysis: The origin of a two-person psychology and empathic perspective. (pp. 152-175). London: Routledge.

Balint, M. (1948). On the psycho-analytic training system. The International Journal of PsychoAnalysis, 29, 163-173.

Balint, M. (1954). Analytic training and training analysis. The International Journal of PsychoAnalysis, 35, 157-162.

Balint, M. (1968). The basic fault. London: Tavistock Publications.

Balint, M. (1970). La genèse de mes idées. Gazette médicale de France 77. 
Balint, M. \& Balint, A. (1939). On transference and countertransference. In Primary love and psycho-analytic technique. (pp. 214-216). London: Tavistock Publications, 1965.

Baraitser, L. (2017). Enduring time. London: Bloomsbury Publishing.

Bergmann, M. S. (1996). The tragic encounter between Freud and Ferenczi. In P. Rudnytsky, A. Bokay and P. Giampieri-Deutsch (Eds.), Ferenczi's turn in psychoanalysis (pp. 145-159). New York: New York University Press.

Berman, E. (2000). Psychoanalytic supervision: The intersubjective development. The International Journal of Psychoanalysis, 81, 273-290.

Berman, E. (2014). Psychoanalytic supervision in a heterogeneous theoretical context: Benefits and complications. Psychoanalytic Dialogues, 24, 525-531.

Bollas, C. (1987). The shadow of the object: Psychoanalysis of the unthought known. London: Free Association Books.

Cassorla, R. M. S. (2001). Acute enactment as a 'resource' in disclosing a collusion between the analytical dyad. International Journal of Psychoanalysis, 82, 1155-1170.

Doehrman, M. J. (1976). Parallel processes in supervision and psychotherapy. Bulletin of the Menninger Clinic, 40, 3-104.

Dunker, C. I. L. (2018). Lógica e ética da supervisão: A constituição do caso clínico. In M. L. Tourinho Moretto \& D. Kupermann (Eds.), Supervisão: A formação clínica na psicologia e na psicanálise (pp. 45-54). São Paulo: Zagadoni.

Ferenczi, S. (1912). Transitory symptom-constructions during the analysis. In First contributions to psycho-analysis. E. Jones (Trans.). (pp. 193-212). London: Karnac Books. 
Ferenczi, S. (1913). Taming of a wild horse. In Final contribution to the problems and methods of psychoanalysis. M. Balint (Ed.), E. Mosbacher, et al. (Trans.). (pp. 336-340). London: Karnac Books.

Ferenczi, S. (1929). The principle of relaxation and neocatharsis. In Final contribution to the problems and methods of psychoanalysis. Ed. M. Balint, E. Mosbacher et al. (Trans.). (pp. 108-125). London: Karnac Books.

Ferenczi, S. (1930). Fantasies on a biological model of super-ego formation. In Final contributions to the problems and methods of psycho-analysis. M. Balint (Ed.), E. Mosbacher, et al. (Trans.). (pp. 227-230). London: Karnac Books.

Ferenczi, S. (1932a). The clinical diary of Sándor Ferenczi. J. Dupont (Ed.), M. Balint \& N. Z. Jackson (Trans.). Cambridge, MA: Harvard University Press. 1988.

Ferenczi, S. (1932b). The two extremes: Credulity and skepticism. In Final contribution to the problems and methods of psychoanalysis. M. Balint (Ed.), E. Mosbacher, et al. (Trans.). (pp. 263-264). London: Karnac Books.

Ferenczi, S. (1933). Confusion of tongues between adults and the child. The language of tenderness and of passion. In Final contribution to the problems and methods of psychoanalysis. (pp. 156-167). London: Karnac Books. 1994. Also in International Journal of Psychoanalysis, 30, 225-230, published in 1949.

Fleming, J., \& Benedek, T. (1966). Psychoanalytic Supervision. New York: Grune \& Stratton.

Freud, S. (1937) Analysis terminable and interminable. Standard edition, Vol. 23, (pp. 211-253). London: Hogarth.

Freud, S. and Ferenczi, S. (1908-1914). The correspondence for Sigmund Freud and Sándor Ferenczi, Volume 1. 1908-1914. E. Brabant, E. Falzeder \& P. Giampieri-Deutsch (Eds.), 
P. T. Hoffer (Trans.), With an Introduction by A. Haynal. Cambridge, Mass/ London, England: The Belknap Press of Harvard University Press. 1992.

Freud, S. and Ferenczi, S. (1914-1919). The correspondence for Sigmund Freud and Sándor Ferenczi, Volume 2. 1914-1919. E. Falzeder \& E. Brabant, (Eds.), P. T. Hoffer (Trans.), With an Introduction by A. Hoffer. Cambridge, Mass/ London, England: The Belknap Press of Harvard University Press. 1996.

Freud, S. and Ferenczi, S. (1920-1933). The correspondence for Sigmund Freud and Sándor Ferenczi, Volume 3, 1920-1933. E. Falzeder \& E. Brabant (Eds.), with the collaboration of P. Giampieri-Deutsch under the supervision of A. Haynal. P. T. Hoffer (Trans.) With and Introduction by J. Dupont. Cambridge, Mass/ London, England: The Belknap Press of Harvard University Press. 2000.

Frijling-Schreuder, E.C. (1970). On individual supervision. International Journal of Psychoanalysis, 51, 363-370.

Harris, A., \& Kuchuck, S. (Eds.). (2015). The legacy of Sándor Ferenczi: From ghost to ancestor. London: Routledge.

Haynal, A. (1997). The Freud-Ferenczi relationship and its bearing on contemporary psychoanalysis. East Central Europe, 24, 27-38.

Haynal, A. (1999). The countertransference in the work of Ferenczi. The American Journal of Psychoanalysis, 59, 315-331.

Issacharoff, A. (1982). Countertransference in supervision-Therapeutic consequences for the supervisee. Contemporary Psychoanalysis, 18, 455-472.

Kernberg, O. F. (1996). Thirty methods to destroy the creativity of psychoanalytic candidates. International Journal of Psychoanalysis, 77, 1031-1040. 
Kovács, V. (1936). Training- and control-analysis. The International Journal of Psycho-Analysis, $17,346-354$.

Kupermann, D. (2018). O ‘Chiaroscuro’ da supervisão psicanalítica. In M. L. Tourinho Moretto \& D. Kupermann (Eds.), Supervisão: A formação clínica na psicologia e na psicanálise (pp. 31-44). São Paulo: Zagadoni.

Kutter, P. (2002). From the Balint method toward profession-related supervision. American Journal of Psychoanalysis, 62, 313-325.

Leader, D. (2010). Some thoughts on supervision. British Journal of Psychotherapy, 26, 228-241.

Mann, T. (1924). The Magic Mountain [Der Zauberberg]. Fisher Verlag, Berlin.

Mészáros, J. (2009). Contribution of Hungarian psychoanalysts to psychoanalytic psychosomatics. American Journal of Psychoanalysis, 69, 207-220.

Ogden, T. H. (2004). This art of psychoanalysis: Dreaming undreamt dreams and interrupted cries. International Journal of Psychoanalysis, 85, 857-877.

Ogden, T. H. (2005). On psychoanalytic supervision. International Journal of Psychoanalysis, 86, $1265-1280$

Roazen, P. (1983). Helene Deutsch, MD: On Supervised Analysis: Introduction. Contemporary Psychoanalysis, 19, 53-58.

Safra, G. (2018). A Experiência de supervisão na graduação: Espaço potencial, polifonia e formação. In M. L. Tourinho Moretto \& D. Kupermann (Eds.), Supervisão: A formação clínica na psicologia e na psicanálise (pp. 45-54). São Paulo: Zagadoni.

Schneider, M. (1988). Le trauma et la filiation paradoxale: de Freud à Ferenczi. Paris: Ramsay.

Searles, H. (1955). The informational value of the supervisor's emotional experience. In Collected Papers on Schizophrenia. New York: Int. Univ. Press, 1965. 
Soreanu, R. (2016). Ferenczi's times: The tangent, the segment, and the meandering line. American Imago, 73, 51-69.

Soreanu, R. (2018a). Working-through collective wounds: Trauma, denial, recognition in the Brazilian uprising. London: Palgrave.

Soreanu, R. (2018b). The psychic life of fragments: Splitting from Ferenczi to Klein. The American Journal of Psychoanalysis, 78, 421-444.

Soreanu, R. (2019). Michael Balint's word trail: The 'ocnophil', the 'philobat', and creative dyads. Psychoanalysis \& History, 21, 53-72.

Spurling, L. S. (2008). Is there still a place for the concept of 'therapeutic technique'? Psychoanalytic Quarterly, 69, 195-223. International Journal of Psycho-Analysis, 89, $523-540$.

Stimmel, B. (1995). Resistance to awareness of the supervisor's transferences with special reference to the parallel process. International Journal of Psychoanalysis, 76, 609-618.

Szőnyi, G. (2014). The vicissitudes of the Budapest Model of supervision: Can we learn from it today? Psychoanalytic Inquiry, 34, 606-618.

Yerushalmi, H. (2012). Intersubjective supervision of psychotherapy with chronically ill patients. Psychoanalytic Social Work, 19, 155-166.

Yerushalmi, H. (2018). Loneliness, closeness and shared responsibility in supervision. The American Journal of Psychoanalysis, 78, 231-246.

Young-Bruehl, E., \& Schwartz, M. M. (2012). Why psychoanalysis has no history. American Imago, 69, 139-159.

\section{NOTES}


${ }^{1}$ Raluca Soreanu is the Wellcome Trust Fellow in Medical Humanities at the Department of Psychosocial Studies, Birkbeck College, London; Psychoanalyst, Effective Member of Círculo Psicanalítico do Rio de Janeiro; Member of The College of Psychoanalysts-UK. $\mathrm{PhD}$ in Sociology, University College London; she is the author of Working-through Collective Wounds: Trauma, Denial, Recognition in the Brazilian Uprising (Palgrave, 2018).

2 To put this idea in Ferenczian terms, we can refer to analysis as a "dialogue of unconsciouses" (Ferenczi, 1932a, p. 84).

${ }^{3}$ As Berman (2014) argues, there are certain degrees of overlap between the contents of analysis and supervision, which brings the need for a continuous exploration of their interactions, within analysis and often times within supervision as well: "Each candidate-analyst-supervisor triangle may arouse new meaningful issues and the significance given to the different figures may not match their declared functions" (Berman, 2014, p. 283).

${ }^{4}$ This formulation refers to the spirit of all Budapest School supervision practices, irrespective if the supervision is carried out on the couch or not.

${ }^{5}$ Other voices after Balint point to various aspects of the dangers of indoctrination, to the discouragement of innovation, and to psychoanalytic candidates developing an imitative and submissive "false analytic self" (Berman, 2014, p. 525; Kernberg, 1996).

${ }^{6}$ For a discussion on the space of supervision as a polyphonic space, see Safra (2018).

${ }^{7}$ For an exploration of supervision and ethics, see Dunker (2018).

${ }^{8}$ As Balint (1948, p. 166) argues: "Although eventually an agreement was reached that analysis of the counter-transference must form an essential part of the training, i.e. training analysis and practical work cannot be divided, no decision could be reached on the point whether the training analyst or another should begin the supervision with the candidate. There were strong arguments both for and against it. As the summary of the discussion at the second Four Countries' Conference stated we shall need further experience before coming to any decision on that point. In spite of this, without any further published discussion the new London Standing Rules (1947) state: 'The analyst undertaking the student's personal analysis does not undertake the supervision of his cases.' So far as we know, this statement is not the result of carefully planned and controlled observations; it sounds to me like yet another dogmatic compulsory ruling." 